\title{
A TUTELA DOS DIREITOS FUNDAMENTAIS: O DIREITO À PROPRIEDADE X A PROTEÇÃO DO TRABALHADOR
}

\section{THE PROTECTION OF FUNDAMENTAL RIGHTS: THE RIGHT TO PROPERTY X THE WORKMAN PROTECTION}

Suzéte da Silva Reis ${ }^{1}$

\section{Resumo:}

O art. $1^{\circ}$ da Constituição Federal de 1988 dispõe que a República Federativa do Brasil tem, dentre seus fundamentos, a dignidade da pessoa humana (inciso III) e os valores sociais do trabalho e da livre iniciativa (inciso IV). $\mathrm{O}$ art. $5^{\circ}$, que trata dos direitos e garantias individuais, em seu inciso X, estabelece que são invioláveis a intimidade, a vida privada, a honra e a imagem das pessoas, assegurado o direito a indenização pelo dano material ou moral decorrente de sua violação e no inciso XXII dispõe que é garantido o direito de propriedade. Em face desses dispositivos, na esfera laboral ainda se encontram inúmeras situações que ensejam uma análise mais detalhada a respeito da aplicabilidade desses direitos, porque, no decorrer da contratualidade ocorrem inúmeras situações nas quais o direito de propriedade, exercido pelo empregador, conflitua com o direito à propriedade intelectual e o direito à privacidade e intimidade do empregado. Trata-se, em verdade, da necessidade de compreender os princípios que asseguram o respeito aos direitos fundamentais, sopesando os mesmos na análise do caso em concreto.

\section{Palavras-chave:}

Direito à propriedade. Direitos fundamentais. Proteção à privacidade. Relações de trabalho.

\footnotetext{
${ }^{1}$ Doutoranda em Direito pela Universidade de Santa Cruz do Sul - UNISC. Mestre em Direito - Área de Concentração Políticas Públicas de Inclusão Social, pela mesma Universidade. Membro do Grupo de Pesquisa "Direitos Humanos de Crianças, Adolescentes e Jovens", ligado ao PPGD - Mestrado e Doutorado em Direito da UNISC. Advogada. Professora de Direito do Trabalho da UNISC. Professora de Cursos de Especialização em diversas instituições de ensino superior. E-mail: sreis@unisc.br
} 


\begin{abstract}
Abstratc:
The first article of the 1988 Constitution provides that the Federative Republic of Brazil has, among its grounds, the dignity of the human person (section III) and the social values of work and free enterprise (section IV). The article 5, which deals with individual rights and guarantees, in your item $\mathrm{X}$, states that are inviolable intimacy, privacy, honor and image of persons, guaranteed the right to compensation for property or moral damages resulting from the violation and item XXII provides that it is guaranteed the right to property. In the face of these devices, in the labor market are still many situations that cause a more detailed analysis regarding the applicability of these rights because, during the contractuality occur numerous situations in which the right of ownership exercised by the employer conflict with the law intellectual property and the right to privacy and employee privacy. It is, in fact, the need to understand the principles that ensure respect for fundamental rights, weighing them in the analysis of the particular case.
\end{abstract}

Keywords:

Right to property. Fundamental rights. Privacy protection. Labor relations.

\title{
Introdução
}

As relações que se estabelecem no âmbito do trabalho, em determinados momentos, são pautadas por conflitos. De um lado, estão os interesses dos empregadores. De outro, os interesses dos empregados. Porém, não é apenas uma questão de interesses, na medida em que ambos possuem direitos que estão constitucionalmente garantidos.

O direito à propriedade, incluindo-se, dentre eles, a proteção da propriedade intelectual, muitas vezes conflitua com os direitos de proteção ao trabalho dos empregados. Noutras situações, são os direitos à privacidade e à intimidade dos trabalhadores que se constituem no mote de discussão. Inúmeras são as situações que provocam conflitos: direitos sobre a produção e a criação intelectual, utilização de email corporativo e monitoramento por parte do empregador, violação do direito à propriedade e do direito à intimidade, dentre outros. 
O presente trabalho pretende, em linhas gerais, discutir acerca da necessidade de se buscar o equilíbrio entre a tutela dos direitos de propriedade, incluindo-se a propriedade intelectual, e o direitoà intimidade e privacidade assegurados aos trabalhadores. Ambos são direitos fundamentais, com assento constitucional, e que dispõe de uma ampla proteção. Entretanto, em algumas situações, poderão ocorrer situações que configuram a violação ou ameaça de violação a esses direitos.

Os princípios que fundamentam o direito do trabalho, assim como a proteção à propriedade que é assegurada pelo texto constitucional, necessitam ser interpretados à luz do princípio da função social da propriedade e da dignidade da pessoa humana. O equilíbrio entre esses direitos é fundamental para assegurar que as relações de trabalho sejam pautadas pela garantia e proteção dos mesmos.

\section{0 direito à propriedade}

Ao tratar do tema do direito à propriedade e das relações de trabalho é preciso ter clareza de quais direitos estão sendo tutelados, e qual a medida da proteção que é assegurada, seja à propriedade, seja aos direitos fundamentais dos trabalhadores.

No Brasil, o direito à propriedade está assegurado pela Constituição Federal de 1988. O art. $5^{\circ}$ do texto constitucional dispõe que a propriedade é uma garantia inviolável do indivíduo, enquanto o inciso XXII do mesmo artigo garante o direito de propriedade. O art. 170 dispõe que a propriedade privada é um dos princípios da ordem econômica. Entretanto, o direito à propriedade não é absoluto.

O próprio texto constitucional estabelece algumas restrições, tal qual a estabelecida no art. 243 que determina a expropriação, sem direito à indenização, das glebas de qualquer região do País onde foram localizadas culturas ilegaisde plantas psicotrópicas e no art. 190, que regula e limita a aquisição ou arrendamento de propriedade rural por pessoa física ou jurídicaestrangeira.

A função social da propriedade está assegurada no art. 50, inciso XXIII da Constituição Federal que estabelece que a propriedade deverá atender a sua função 
social. Os artigos 184 e 185 tratam da função social da propriedade rural, prevendo, dentre outros, a desapropriação para reforma agrária.

Com isso, se verifica que a propriedade, além do direito de uso, gozo e disposição por parte de seu titular, deve atender à função social que lhe é inerente, a partir do seu uso racional.

Mas não apenas a propriedade material está protegida e amparada. A proteção constitucional estende-se à propriedade intelectual, garantindo aos seus titulares um vasto elenco de garantias pertinentes. Temos as leis $n^{\circ}$. 9.279 e $n^{0}$. 9.610/98, que regulam, respectivamente, os direitos e obrigações relativos à propriedade industriale o direito de autor.

Conforme Aronne (2013, p. 232), a garantia da propriedade enquanto direito fundamental assegurada pela a Constituição Federal alcança “toda a esfera patrimonial, seja material ou não, possível de apropriação privada”. O autor destaca, ainda, a funcionalização desses direitos e a sua projeção para a ordem social e econômica.

A propriedade intelectual é “aquela que recai sobre os bens intangíveis resultantes das concepções da inteligência, da estética, da utilidade e do trabalho intelectual, encarados principalmente sob o aspecto do proveito material que deles pode resultar” (BASSO, 2013, p. 325). A autora refere que a proteção constitucional estendese para além dos direitos patrimoniais, pois o “direito de propriedade não compreende apenas a propriedade material, porém, tem um amplo sentido” (BASSO, 2013, p. 328).

Em relação à propriedade industrial, Basso (2013, p. 333) refere que é justo “assegurar ao inventor e autor de criações industriais privilégio exclusivo de exploração econômica e industrial sobre seus inventos e progressos à técnica, durante determinado período”.

Contudo, mesmo com a edição de legislações específicas acerca do tema, as mesmas nem sempre dão conta das situações fáticas. No que concerne às relações laborais, inúmeras situações ensejam uma análise mais detalhada e aprofundada acerca dessas garantias e dessa proteção. Muitas vezes, não se tem ao certo quem é o titular 
desse ou daquele direito. Com isso, é preciso realizar uma apreciação do caso concreto para verificar quem detém a titularidade sobre o direito.

É o que ocorre nos casos em que se discute a autoria de determinada invenção ou modelo de utilidade. Embora regulada pelo art. 88 da Lei $n^{0}$. 9.279, que dispõe que o empregador é o proprietário da invenção ou do modelo de utilidade quando o empregado for contratado para realizar a pesquisa ou a atividade inventiva, muitas vezes o empregado busca a tutela judicial para declarar que ele é o inventor e, por consequência, o proprietário.

Para ter assegurado o direito de proteção - e de eventual indenização decorrente da invenção ou autoria de modelo de utilidade, o empregado deve comprovar que, efetivamente, desenvolveu o mesmo fora do seu horário de trabalho, ou com instrumentos não pertencentes ao empregador. Para ilustrar, a recente decisão proferida pelo Tribunal Regional do Trabalho da 4 a Região, colacionada abaixo:

\footnotetext{
RECURSO ORDINÁRIO DO RECLAMANTE. PROPRIEDADE INDUSTRIAL. INDENIZAÇÃO. LEI 9.279/1996 - PROPRIEDADE INDUSTRIAL. Ausência de prova de que a máquina existente na empresa e aperfeiçoada pelo empregado possuísse qualidade de "nova", fora do conceito de estado da técnica daquele tempo, sendo capaz de agregar melhoria tecnológica a outros equipamentos existentes na indústria como um geral e não somente na empresa em que trabalhava. Além disso, a prova pericial e a prova oral revelam que o estudo e melhoria dos equipamentos estavam inseridos dentro das atividades inerentes às funções ocupadas pelo empregado. Provimento negado. Processo ${ }^{\circ}$. 0001087-84.2012.5.04.0405 (RO). Órgão Julgador: $8^{\mathrm{a}}$ Turma. Redator: Juraci Galvão Junior. Data: 30.10.2014. Origem: $5^{\text {a }}$ Vara do Trabalho de Caxias do Sul.
}

No caso em análise, o empregado pleiteava o pagamento de indenização decorrente das melhorias efetuadas em uma máquina do empregador que se encontrava sem uso no depósito. Segundo o empregado, o seu projeto conferiu uma nova forma e desenho ao equipamento, o que gerou a melhoria na produtividade e na qualidade das peças produzidas, além da redução de custos e diminuição da mão de obra.O empregador, por sua vez, alegou que o empregador fora contratado para realizar essas atividades, não sendo devida qualquer indenização. 
A justiça do trabalho, amparada nos artigos 88 a 92 da Lei $n^{\circ}$. 9.279/1996 entendeu que, apesar de comprovado que o empregado realizou melhorias no equipamento, o desenvolvimento e a introdução de tecnologia já existente na empresa não caracteriza a invenção, criação ou modelo protegidos pelos artigos 13 e 14 da referida lei. Ademais, para comprovar a qualidade de “nova”, a tecnologia desenvolvida deveria ter aplicabilidade em outros equipamentos, não apenas no equipamento da empresa na qual trabalhava.

Porém, a questão central foi análise de que se o aperfeiçoamento das máquinas contidas no estabelecimento eram ou não atividades inerentes à função ocupada pelo empregado, que havia sido contratado para trabalhar no setor de engenharia do processo, sendo responsável pelo estudo da linha e célula produtiva para início das operações e pela validação das operações de produção das peças e componentes de freio.

Nesse sentido, vale transcrever parte da sentença:

...as obrigações do empregado eram de meio não fim, o que torna inegável
que as tarefas do autor, quais sejam, de aprimoramento do maquinário, eram
diretamente relacionadas ao desenvolvimento da atividade preponderante da
ré, isto é, à indústria metalúrgica, o que, por si só, elidiria o direito daquele de
auferir indenização suplementar ao salário mensal. A contraprestação do
salário já abrangia a execução de tarefas relacionadas ao circunstancial
incremento do empreendimento econômico da empregadora.

Por fim, a justiça do trabalho entendeu que o fato do empregador ter auferido maiores ganhos em decorrência das melhorias efetuadas pelo empregado no equipamento, não há qualquer possibilidade de indenização, pois as melhorias desenvolvidas encontravam-se inseridas nas atividades para as quais o empregado fora contratado e pelas quais recebia remuneração mensal.

Noutra situação, em julgamento do Agravo de Instrumento em Recurso de Revista $n^{\circ}$. 47441-58.2008-5.03.0043, no ano de 2013, houve entendimento diverso no Tribunal Superior do Trabalho, conforme ementa abaixo colacionada:

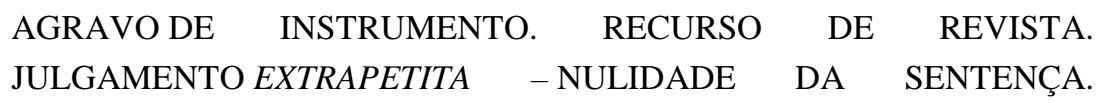


I N DENIZAÇÃO - INVENÇÃO DE MAQUINÁRIO - LEI No 9.279/96 CONTRIBUIÇÃO PESSOAL DO EMPREGADO NO APERFEIÇOAMENTO DA MÁQUINA - "JUSTA REMUNERAÇÃO" DEVIDA. Nega-se provimento a agravo de instrumento que visa liberar recurso despido dos pressupostos de cabimento. Agravo desprovido.(TST AIRR 474415820085030043 47441-58.2008.5.03.0043)

Nesse caso, quando da análise do conjunto probatório, a justiça do trabalho entendeu que o empregado, conforme disposição do art. $8^{\circ}$ da Lei $n^{\circ}$. 9.279/96 realizou ato de aperfeiçoamento em uma máquina, caracterizando a invenção. Mesmo exercendo as suas funções no Departamento de Engenharia do empregador, o empregado extrapolou os limites da sua função de acompanhamento do projeto para contribuir pessoalmente para o aperfeiçoamento do projeto.

Mesmo fazendo uso dos recursos da empresa, restou comprovado que foi ultrapassada a condição funcional de técnico por parte do empregado, passando a atuar no campo inventivo, definindo-se o direito do empregado participante em aperfeiçoamento de invento e, como consequência, participar dos ganhos econômicos que resultaram da exploração da patente por parte do empregador. Por essa razão, o empregador foi condenado ao pagamento de indenização nos termos do art. 89, parágrafo único combinado com o art. 91, § $2^{\circ}$ da Lei nº 9.279/96.

Para Basso (2013, p. 335), a Lei nº 9.279/96 “reafirma a intenção do legislador constitucional ao sujeitar a concessão desses direitos a condições especiais de finalidade: o interesse social e o desenvolvimento econômico e tecnológico do Brasil”.

Porém, muito além da discussão acerca da indenização, ou do valor a que tem direito o empregado autor de invenção ou de modelo de utilidade, a questão mais relevante diz respeito ao contrato de trabalho. Melhor explicando: é propriedade do empregador a invenção ou modelo de utilidade quando o empregado for contratado para executar essas funções e quando os instrumentos sejam de propriedade do empregador.

Na prática, muitas vezes ocorre a contratação para o desenvolvimento de determinadas funções, porém, no decorrer do contrato de trabalho, o empregado passa a desenvolver funções distintas ao previsto inicialmente, sem o recebimento da justa 
contrapartida. É essa uma das situações ensejadoras dos pedidos de reparação e de indenização pleiteados junto à justiça do trabalho.

Noutros casos, o empregado desenvolve o invento ou modelo de utilidade fora do seu horário de trabalho, ainda que utilizando os instrumentos e equipamentos de propriedade do empregador. Da mesma forma, será devida a indenização ou a justa remuneração decorrente da atividade inventiva.

As relações de emprego encontram-se amparadas pelo texto constitucional, especialmente em seu art. $7^{\circ}$, assim como pela legislação infraconstitucional, notadamente a Consolidação das Leis do Trabalho (CLT). Para Coutinho (2013, p. 550), o trabalho é e sempre foi “a categoria-chave econômica e social central da sociedade”, constituindo-se no núcleo central e no referencial simbólico da sociedade moderna.

O trabalho está presente na vida de cada um cotidianamente. É através dele “que o sujeito se constitui como ser social nas relações que trava, reconhecendo-se a partir da própria transcendência, objetivada na atividade e no resultado (BASSO, 2013, p. 550). Desse modo, as relações de trabalho, de modo geral, e as de emprego, de maneira mais específica, estão amparadas constitucionalmente.

A proteção destinada aos trabalhadores tem como fundamento o art. $6^{\circ}$ da Constituição Federal que estabelece que o trabalho é um direito fundamental social. Como tal, é detentor de uma vasta proteção. A relação de emprego, constituída por duas partes que estão em condição de desigualdade, sendo que, jurídica e economicamente, o empregador está em posição mais vantajosa, é alvo da mais ampla proteção.

Isso ocorre porque as relações de emprego estão ao abrigo da legislação trabalhista e amparadas pelos princípios peculiares dessa disciplina. Alonso Garcia (1960, p. 247) refere que os princípios são "linhas diretrizes ou postulados que inspiram o sentido das normas trabalhistas e configuram a regulamentação das relações de trabalho, conforme critérios distintos dos que podem encontrar-se em outros ramos do direito". 
Para Barros (2012, p. 141), esses princípios têm como "funções informar o legislador, orientar o Juiz na sua atividade interpretativa, e, por fim, integrar o direito, que é sua função normativa”.

Um dos mais significativos princípios é o da proteção, que é o princípio basilar do Direito do Trabalho. De acordo com Delgado (2014), esse princípio informa que o Direito do Trabalho possui, em seu interior, uma teia de regras, institutos, princípios e presunções próprias que visam assegurar um equilíbrio nas relações trabalhistas, tendo em vista que o empregado, na relação jurídica de emprego, é a parte hipossuficiente.

Esse princípio, segundo a doutrina trabalhista, é o mais importante, na medida em que influencia em toda a estrutura e interpretação do direito laboral. A jurisprudência, da mesma forma, utiliza-se desse princípio como critério hermenêutico.

Delgado (2014) refere que o princípio da proteção desdobra-se nos demais princípios que sustentam o direito do trabalho. Segundo o autor, o reconhecimento da desigualdade socioeconômica e de poder entre o empregado e o empregador implica na proteção especial aos interesses do trabalhador, que está em posição economicamente inferior a do empregador.

Para Barros (2012, p. 142), o princípio da proteção “consiste em tentar corrigir desigualdades, criando uma superioridade jurídica em favor do empregado, diante da sua condição de hipossuficiente”. As relações de emprego estão pautadas pela subordinação jurídica e econômica do empregado em relação ao empregador. A dependência e a subordinação do primeiro em relação ao segundo é determinante quando da interpretação e análise do caso concreto.

Outro princípio importante que contribui para a solução dos conflitos ora analisados, envolvendo a propriedade intelectual, é o princípio da primazia da realidade sobre a forma. Para Delgado (2014), o conteúdo do contrato de trabalho não se restringe ao que está disposto no respectivo instrumento escrito. 
Barros (2012) defende que são as situações de fato que definem as relações jurídico-trabalhistas e que a forma através da qual se realizou a prestação do serviço sobrepõe-se ao nome que foi atribuído pelas partes.

No mesmo sentido, Martinez (2014, p. 120) leciona que o princípio da primazia da realidade "baseia-se no mandamento nuclear protetivo segundo o qual a realidade dos fatos prevalece sobre meras cláusulas contratuais ou registros documentais, ainda que em sentido contrário”. Entretanto, o autor faz uma ressalva e destaca que o princípio da primazia da realidade aplica-se tanto a favor quanto contra o empregado, na medida em que os fatos extraídos da realidade é que são valorizados, em detrimento dos documentos, que podem ter seu conteúdo alterado ou forjado.

O contrato de trabalho incorpora todas as situações fáticas que decorrem da prestação do serviço. Assim, mesmo havendo a previsão expressa no contrato de trabalho das atividades e funções que serão desempenhadas pelo empregado no curso da contratualidade, se restar comprovado que de fato as funções e atividades exercidas eram outras, as últimas é que prevalecerão.

Esses dois princípios, juntamente com os demais que orientam o Direito do Trabalho, servem de fundamento para inúmeras decisões que determinam a indenização ao empregado decorrente da autoria ou invento. Contudo, frise-se que não há nenhuma violação ao direito de propriedade ou a legislação específica que disciplina a propriedade intelectual.

\section{2. $\mathrm{O}$ direito à privacidade e à intimidade dos trabalhadores e a reparação por danos morais}

Um tema passível de discussão e que suscita posições divergentes é quanto ao direito de privacidade e intimidade dos trabalhadores, assegurados pela Constituição Federal de 1988 em confronto com o direito de propriedade do empregador, exemplificativamente naquelas situações em que ocorre a violação do e-mail corporativo ou monitoramento do local de trabalho sem o devido conhecimento por parte dos empregados. 
O fornecimento de e-mail corporativo ao empregado ocorre em razão das atividades a serem desempenhadas ao longo do contrato de trabalho. O e-mail destina-se a utilização dentro do horário de trabalho pelo empregado. Computadores e o domínio do e-mail são propriedade do empregador, que poderá restringir o uso do mesmo, estabelecendo critérios claros e bem definidos para sua utilização.

Não há que se falar em violação quando o empregador determina, expressamente, que é proibido utilizar o e-mail corporativo para fins pessoais ou qualquer outro fim que não seja o desenvolvimento da atividade laboral. Afinal, o empregado é contratado para desempenhar determinadas funções, para as quais recebe a contrapartida salarial. Durante a sua jornada de trabalho, portanto, deverá respeitar as regras estabelecidas e cumprir as suas funções.

É preciso, porém, que o empregador deixe muito claro o que é e o que não é permitido, para evitar futuras situações ensejadoras de violações, tanto por parte do empregado quanto por parte dos prepostos do empregador.

O monitoramento do e-mail corporativo, por si só, não representa violação à esfera privada do empregado. Contudo, é preciso ter claro que o art. $5^{\circ}$ da Constituição Federal de 1988, ao estabelecer que a inviolabilidade da intimidade e da privacidade, bem como o sigilo da correspondência são direitos fundamentais e, como tais, estão protegidos.

Contemporaneamente não resta dúvida que o e-mail é também uma forma de correspondência, substituindo a correspondência escrita. No entanto, a discussão acerca do e-mail corporativo é mais ampla. Enquanto o mesmo é uma ferramenta de trabalho, há uma corrente que entende que está dissociado da vida privada e que, portanto, o empregador tem o direito de monitorar o seu uso. A justificativa é que a utilização indevida do e-mail corporativo pode vir a macular ou comprometer a imagem do empregador - que também tem o direito fundamental de proteção a imagem assegurado pelo texto constitucional. 
Noutro sentido, que entende a proteção constitucional de forma mais ampla, qualquer violação ao e-mail, mesmo que corporativo, seria uma violação à esfera privada do empregado, razão pela qual o mesmo deveria ser indenizado.

Por outro lado, o empregado também está sujeito às mesmas regras no que concerne ao e-mail, considerado como correspondência e que é objeto de proteção. Desse modo, qualquer violação implica na aplicação de penalidades. A utilização indevida do e-mail corporativo fornecido pelo empregador, assim como a violação da correspondência eletrônica do empregador configuram-se como prática ilícita.

Nesse sentido, o julgamento abaixo demonstra a proteção conferida à correspondência eletrônica:

$$
\begin{aligned}
& \text { RECONVENÇÃO. DANO MORAL À PESSOA JURÍDICA. } \\
& \text { APROPRIAÇÃO INDEVIDA DE CORRESPONDÊNCIA ELETRÔNICA E } \\
& \text { FURTO DE INFORMAÇÕES SIGILOSAS DE PROPRIEDADE DO } \\
& \text { EMPREGADOR. INDENIZAÇÃO DEVIDA PELO EMPREGADO. } \\
& \text { Demonstrada a ocorrência de apropriação de informação confidencial pelo } \\
& \text { empregado, sem a devida autorização do empregador, está configurado o } \\
& \text { crime de furto eletrônico ou cibernético, sendo devida a indenização por dano } \\
& \text { moral à empresa em face da violação de seu direito de manter em sigilo } \\
& \text { dados estratégicos restritos à corporação. (...). Acórdão Processo no }{ }^{\circ} \text {. } \\
& \text { 0000295-37.2011.5.04.0027 (RO). Redator: João Paulo Lucena. Órgão } \\
& \text { Julgador: } 10^{a} \text { Turma. Origem: } 27^{a} \text { Vara do Trabalho de Porto Alegre. Data: } \\
& \text { 13.03.2014. }
\end{aligned}
$$

A proteção aos direitos de propriedade e ao sigilo de correspondência são tratados com a mesma atenção. No caso em análise, o empregado foi condenado a indenizar o empregador por crime de furto eletrônico ou cibernético, em razão da apropriação indevida de informações sigilosas do empregador. A proteção, portanto, é extensiva a qualquer das partes da relação laboral.

O tema é polêmico e os tribunais trabalhistas têm buscado verificar em que medida a invasão do e-mail trouxe prejuízos e afrontou os direitos fundamentais do trabalhador e, por outro lado, em que medida a utilização indevida desse e-mail trouxe prejuízos ou comprometeu a imagem do empregador, também direito fundamental.

Se observa, ainda, que durante a contratualidade, em inúmeras ocasiões ocorre a violação aos direitos de propriedade intelectual e autoral dos empregados, muitas delas afetando, inclusive, a esfera íntima e pessoal dos trabalhadores. É o caso da utilização 
das gravações, filmagens, fotos e outros instrumentos para controle e proteção da propriedade.

O controle e monitoramento por câmeras e microfones é objeto de constantes discussões. O ambiente de trabalho pode ser monitorado pelo empregador, tanto para assegurar a proteção da propriedade, tanto quanto para garantir a segurança dos próprios empregados, dependendo do ramo de atividade desenvolvida.

No entanto, essa forma de controle deve respeitar determinados parâmetros, justamente com vistas a assegurar a proteção da privacidade e da intimidade dos trabalhadores, que são invioláveis.

Nesse sentido, é interessante o julgado recente do Tribunal Regional do Trabalho da $4^{\text {a }}$ Região:

INDENIZAÇÃO POR DANOS MORAIS. INSTALAÇÃO DE CÂMERA. PORTA DO BANHEIRO DANIFICADA. VIOLAÇÃO DA INTIMIDADE DO TRABALHADOR. A prova dos autos evidencia que a ré instalou uma câmera de segurança dentro da guarita onde o autor exercia sua função de vigilante. A câmera, todavia, foi instalada exatamente em cima da porta do banheiro, que estava quebrada e com frestas que permitiam a captação de imagens do interior do banheiro, violando, assim, a intimidade dos trabalhadores que dele se utilizavam para troca de roupas e para suas necessidades fisiológicas. O ultraje à esfera extrapatrimonial obreira é mais do que evidente na espécie e dispensa a prova de sua efetividade, pois o dano moral, enquanto resultante de violação à honra e intimidade da pessoa é definido, pela legislação, ilícito de ação, e não de resultado, de modo que o dano se esgota em si mesmo (na ação do ofensor) e dispensa a prova do resultado. Indenização por danos morais devida, com fulcro (...).Acórdão Processo nº. 0000058-72.2013.5.04.0531 (RO). Redator: Marcelo José Ferlin D’Ambrósio. Órgão Julgador: $2^{\text {a }}$ Turma. Origem: Vara do Trabalho de Farroupilha. Data: 05.02.2015.

Trata-se de uma ação movida por um empregado contra uma loja de móveis, da qual era empregado. A instalação das câmeras de vigilância à entrada do vestiário constitui violação ao art. $5^{\circ}$, inciso $\mathrm{X}$ da Constituição Federal, que dispõe que a honra e a imagem da pessoa são invioláveis. O Relator, no julgamento do Recurso Ordinário supra, utiliza também como fundamento os artigos 186 e 927 do Código Civil, que determinam que aquele que, por ação ou omissão voluntária, negligência ou 
imprudência, violar direito e causar dano a outrem, ainda que exclusivamente moral, comete ato ilícito, ficando obrigado a repará-lo.

Da mesma forma, é a previsão do art. 187 do Código Civil brasileiro que estabelece que "também comete ato ilícito o titular de um direito que, ao exercê-lo, excede manifestamente os limites impostos pelo seu fim econômico ou social, pela boafé ou pelos bons costumes". Para o Relator do Recurso Ordinário, quando configurada a ofensa, não há necessidade de prova relativa ao prejuízo causado, pois o desrespeito aos direitos fundamentais representa a prática do ato ilícito, contrário aos postulados consagrados no texto constitucional.

Dallegrave Neto (2007) leciona que para caracterização do dano moral basta a violação de um direito geral de personalidade. A dor, tristeza e desconforto emocional são sentimentos presumidos que decorrem de tal lesão. Por essa razão, prescindem de comprovação, sendo suficiente comprovar a violação do direito.

Nesse mesmo sentido, o julgado abaixo demonstra o entendimento de que o dano moral decorre da violação de um direito:

INDENIZAÇÃO. DANOS MATERIAIS. REPRODUÇÃO DA VOZ. O art. $7^{\circ}$ da Lei 9.610/98 (Lei de Direitos Autorais) elenca as obras intelectuais protegidas pelo referido diploma legal, contudo o rol ali disposto é meramente exemplificativo, e não taxativo. Assim, o fato não estarem elencadas as mensagens de voz gravadas pela trabalhadora, e reproduzidas comercialmente pela reclamada, não torna inaplicável a Lei de Direitos Autorais. Sendo incontroverso que a concessionária de telefonia reproduz, com intuito comercial, mensagens de voz produzidas pela reclamante, impõese a manutenção da sentença que a condena ao pagamento de indenização pela utilização da voz da trabalhadora. (...). Acórdão Processo nº ${ }^{0}$ 011690032.2007.5.04.0019 (RO). Redator: André Reverbel Fernandes. Órgão Julgador: $9^{\mathrm{a}}$ Turma. Origem: $19^{\mathrm{a}}$ Vara do Trabalho de Porto Alegre. Data: 19.09.2002.

A reprodução da voz, sem autorização do empregado, configura-se violação aos direitos de personalidade, bem como à Lei de Direitos Autorais.

A utilização da imagem, por parte do empregador, com fins comerciais e sem a devida autorização por parte do empregado, é também passível de indenização:

USO DA IMAGEM DO EMPREGADO. FINS COMERCIAIS. INEXISTÊNCIA DE AUTORIZAÇÃO. INDENIZAÇÃO DEVIDA. 
Empregador que, sem autorização, utiliza a imagem do empregado com fins comerciais ou econômicos (ainda que não exclusivamente), deve indenizar o empregado, com fundamento no art. 5º V e X, da CF. (...). Acórdão Processo $n^{\circ}$. 0001639-49.2012.5.04.0405 (RO). Redator: João Paulo Lucena. Órgão Julgador: $8^{\text {a }}$ Turma. Origem: $5^{\text {a }}$ Vara do Trabalho de Caxias do Sul. Data: 17.07.2014.

A proteção à imagem da pessoa é ampla. A divulgação, sem o seu consentimento expresso, para fins de publicidade comercial ou qualquer outro fim, fere o direito individual de personalidade. Com isso, surge o dever de indenização por parte de quem se locupletou com o ilícito à custa de outrem. O direito à imagem "traduz o vínculo que une uma pessoa à sua expressão externa, ao conjunto de traços e caracteres que a individualizam” (BASSO, 2013, p. 331). Isso assegura a pessoa que ninguém possa utilizar sua imagem sem prévia autorização, porque, conforme Basso (2013), o direito à imagem está vinculado aos demais direitos de personalidade e à preservação dos direitos fundamentais da pessoa humana. A imagem de uma pessoa, conforme assevera Sampaio (2013, p. 283), é composta “de seu traço físico, de suas feições, de sua aparência in natura ou representada gráfica, plástica ou fotograficamente”. Nesse sentido, a utilização cada vez mais freqüente de câmaras de vigilância, não apenas por parte dos empregadores, mas também do próprio Estado que age em nome da segurança coletiva, impõe que é preciso conhecer os parâmetros e os limites da utilização da imagem da pessoa. Qualquer violação ao direito constitucional protegido, implica na reparação e/ou indenização por parte de quem cometeu a violação.

\section{Conclusão}

Inúmeras são as situações que envolvem o direito de propriedade e a propriedade intelectual nas relações de trabalho. O presente artigo objetivou abordar algumas das mais relevantes e que ocorrem com mais frequência no dia a dia dos contratos de trabalho. O que não significa que não ocorram outras formas de violação.

A proteção constitucional assegurada aos direitos fundamentais da pessoa, bem como a proteção a propriedade, material e imaterial, ensejam debates e análises constantes, especialmente quando se trata das relações de emprego. A subordinação, jurídica e econômica, do empregado em relação ao seu empregado, garante-lhe uma ampla proteção. No entanto, essa proteção encontra seus parâmetros nos direitos 
fundamentais assentados constitucionalmente. A relação de emprego, protegida e ao abrigo dos princípios constitucionais e infraconstitucionais, especialmente dos princípios peculiares do Direito do Trabalho, não pode ser analisada de forma dissociada ou isolada. Qualquer que seja o objeto de discussão decorrente da relação de emprego no que tange aos direitos de propriedade e personalidade, a análise deverá, sempre, respeitar o princípio da primazia da realidade à luz dos preceitos constitucionais.

\section{Referências}

ALONSO GARCIA, Manoel. Derecho del Trabajo. Barcelona: José Maria Bosch Editor, 1960.

ARONNE, Ricardo. Direito à propriedade. In: CANOTILHO, J.J. Gomes; MENDES, Gilmar Ferreira; SARLET, Ingo Wolfgang; STRECK, Lênio Luiz. Comentários à Constituição do Brasil. São Paulo: Saraiva/Almedina, 2013.

BARROS, Alice Monteiro de. Curso de Direito do Trabalho. $8^{\text {a }}$ ed. São Paulo: LTr, 2012.

BASSO, Maristela. Comentário ao art. 5o, XXVIII da Constituição Federal. In: CANOTILHO, J.J. Gomes; MENDES, Gilmar Ferreira; SARLET, Ingo Wolfgang; STRECK, Lênio Luiz. Comentários à Constituição do Brasil. São Paulo: Saraiva/Almedina, 2013.

DALLEGRAVE NETO, José Afonso.Responsabilidade Civil no Direito do Trabalho. $2^{\text {a }}$ ed. São Paulo: LTr, 2007.

DELGADO, Maurício Godinho. Curso de Direito do Trabalho. São Paulo: LTr, 2014.

MARTINEZ, Luciano. Curso de Direito do Trabalho. São Paulo: Saraiva, 2014.

SAMPAIO, José Adércio Leite. Comentários ao art. $5^{\circ}, \mathrm{X}$ da Constituição Federal. In: CANOTILHO, J.J. Gomes; MENDES, Gilmar Ferreira; SARLET, Ingo Wolfgang; STRECK, Lênio Luiz. Comentários à Constituição do Brasil. São Paulo: Saraiva/Almedina, 2013.

Publicado no dia 04/03/2015

Recebido no dia 22/12/2014

Aprovado no dia 27/02/2015 